\title{
Research on Innovative Inspiration of Internet Thinking on Brand Promotion Design
}

\author{
Zhang $\mathrm{Xu}^{1, \mathrm{a}}$ \\ ${ }^{1}$ Wuhan Institute Of Media, Wuhan, Hubei, China \\ a88356371@qq.com
}

Keywords: Brand Promotion Design, Internet, Advertising

\begin{abstract}
Internet new media precipitated by Internet companies, represented by the new economy, and also inspired the traditional enterprise marketing potential energy, all the companies are using the Internet as a new marketing, sales channels, information exchange, but also to brand competition spread to the Internet. Internet emphasis on corporate brand building deepening brand and quickly occupied the high ground on the Internet, the development of enterprises will play a decisive role. Visual brand image is the brand culture, brand concepts, brands and brand quality brands such as visual symbol of the internal factors, the fine form design and visual effects to convey a brand of course the audience will have a good first impression, but to the consumer psychology to establish a solid brand image, relying solely on the brand's visual identity is not enough, need more brands and brand quality assurance.
\end{abstract}

\section{Theoretical Introduction of Brand Promotion Design}

In essence, the brand positioning is described constitute the fundamental basis of a target consumer group target and to speak of. Formal brand positioning brand managers written description, it can ensure that the brand can be integrated throughout the organization and share the company's vision, and to guide people to the brand strategic thinking. Mining intrinsically linked brand building and between the visual image design in order to look for suitable Chinese brand visual identity development path.

In addition, new media can promote the application of domestic brand visual identity in the early 21 st century to mature. Computer software developed using the brand image of the design process provides a convenient, more advanced printing technology for brand image design applications support. Rapid economic development, created a lot of social wealth, in the new century, accumulated rich material wealth, to enhance training and aesthetic needs of enterprises and commodities to consumers for the requirements and selection criteria are also increasing. Customers not only want to have a good quality of their products, but also hope to buy the products have a good brand image, quality and service culture ${ }^{[1]}$.

Domestic and foreign enterprises will also be regarded as visual brand image design effective means to enhance competitiveness be used, from newspapers to magazines, from TV to the network, from the logo to the packaging, from advertising to integrated marketing, brand image design function is constantly enlarge. Due to continued increasing brand image design services, professional brand image design enterprises have continued to increase, the number of employees is also not unusual. While domestic brand design enterprises and foreign advertising companies, joint planning agency is in a position to compete against each other, and each in the brand image of the design and operation also have different experiences and models, but it is precisely this kind of competition is different, prompting the two can learn from each other and exchange useful experience, so that the domestic brand image design career in the twenty-first century really maturing. 


\section{The Demands Change of Visual Brand Image Design}

In the context of the information age, like a modernist style design in the form of those stereotyped apparently no longer able to meet the needs of a wide audience of design. Brand visual identity design catchy increasingly rich design language and transformation design demands also have a more obvious manifestation. 2000 World's Fair in Hanover, Germany brand logo design known as the "breathing mark", according to different occasions to change the structure and color, while maintaining the overall perception of unity but also the premise of showing a different state of motion. Hannover Expo this series of seemingly biological structure modeling logo design can be said that modern visual brand image design use change means an important symbol, and it provides people with a new perspective to appreciate and examine contemporary brand logo design ${ }^{[2]}$. Fig. 1 shows the Hanover World Expo logo design.

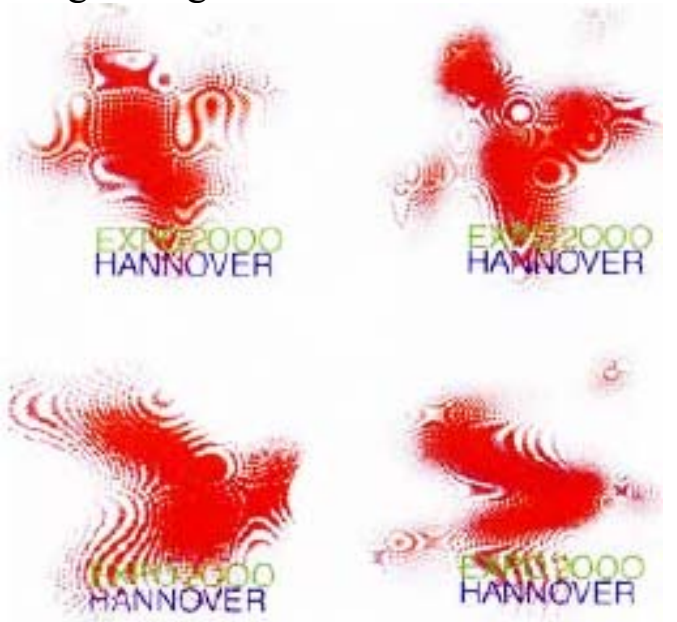

Fig. 1.The Hanover World Expo logo design

In the current era of highly developed material civilization, consumers not only buy the product itself, but also contain a purchase brand value, experience and self-awareness through the colorful. Therefore, a good brand visual identity design, brand logo to the product from the packaging, to the brand website design, all sought to highlight the distinctive brand personality and brand inherent spiritual values as well as emotional care to consumers. Personalized and emotional needs of consumers began to be amplified in a modern and contemporary design activities, personalized, emotional care began to become the focus of attention of contemporary design in shaping the visual brand image design activity is also particularly critical.

We can say that under the background of the information age, visual brand image design not like that relying solely on the pieces of a logo or brand advertising will be able to achieve the desired communication effects. This means that people tend to choose their own experience, heard, or in advertising, driven by the spread of the role of the media and their own emotional needs generated intersection merchandise. Plus covering power today's media and other platforms through the network is constantly expanding, people can enjoy significantly expand their ability to govern themselves and their environment and culture of fun by digital, information technology, created by an extension of the culture. In this process, it is invisible to also expanded choose their own design rights. Not difficult to see, at the height of the information and material abundance era in order to get the best brand communication, brand image design demands change can be said to be the inevitable result ${ }^{[3]}$.

\section{Brand Promotion and Dissemination of the Internet Age}

As the Internet grows, a new virtual world was spawned out, and it's catching up with the richness of the real world. Many social and economic activities can be expanded by the Internet, people's communication methods will also be a fundamental change occurred due to Internet. Internet as a 
new medium of social life twenty-first century to produce a huge impact, "scholar no house, to know something of the world," in the network of the information age has been realized, home office, online shopping has become the contemporary people part of life. Way back in the forties, when television was born, TV advertising is gradually replacing the traditional information media to promote its brand image as an effective conduit, since the advent of television changed the way people access to information selection habits ${ }^{[4]}$.

Internet advertising is the main way their products via the Internet brand advertising. Wherein the web is the most important form of advertising, it can be divided into static, dynamic and interactive three. Static banner on your site is the use of image information dissemination, but its spread effect is not ideal, it is decreasing. Dynamic banner is through the motion of the image information dissemination, compared to a static banner, it can spread more information in a limited space, and also more attractive for the audience, is now mainstream web advertising. Interactive banner ads are directly communicating through the game, problems, etc. and the audience in the form of banner ads, but also three kinds of banners in the most impressive and the highest click rate.

From the perspective of art and design, network to bring people stimulate different senses, to the transmission of visual maps, text, sound, like a form of auditory information, online advertising makes consumers feel more real goods and services, better brand image transfer to consumers. The rapid popularity of the network so that the brand image design from static two-dimensional performance-based, extending to convey three-dimensional dynamic way, from a single media performance while steering multimedia performance. The audience on the network can be multiple perspectives senses to experience the visual brand image to convey a fresh form. When the visual brand image elements are added or other multi-dimensional sound and feeling of being spread out in a dynamic way, the visual image of the brand in terms of design, is definitely a huge leap forward.

\section{The Brand Image Design}

In the eyes of customers to build a good corporate brand, brand image is the key factor. Consumer brand experience more through this brand contact points, to feel the brand brings good feeling, to experience the difference between brands. The formation of their performance, brand image can be divided into internal and external image, internal image mainly include product image and cultural image; the external image of the system including the credibility of the brand identity and brand image in the market, consumers performance. Brand identity system is the consumer and the public perception and evaluation of brand identity system. Initial public evaluation of the brand from its visual image is fine or coarse, brand identity system by the brand to the consumer is the most direct and rapid way. Especially in modern society, greatly enriched products, new product launches are dizzying, catch the consumers' attention, so it may further grab their wallets and hearts ${ }^{[5]}$. Fig.2 shows the brand image design.

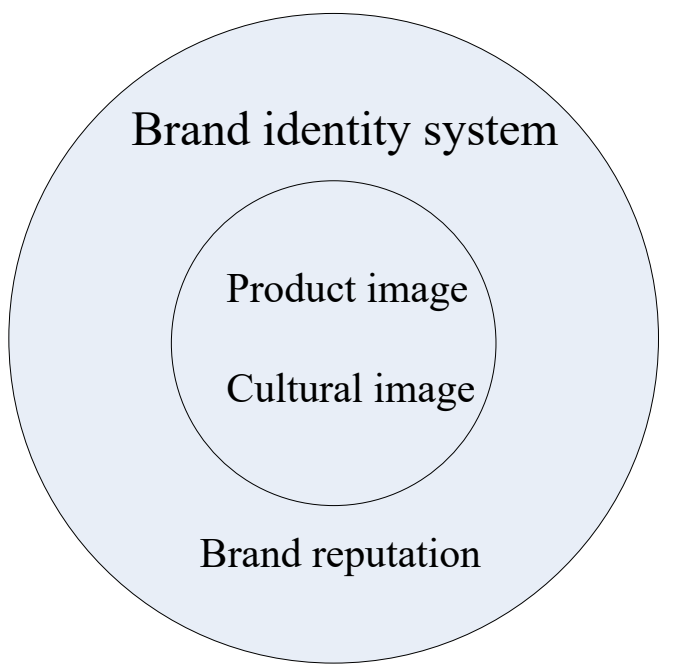

Fig. 2.The brand image design 
As they mature computers, networks, digital technology, people have entered the era of information technology, social life is also gradually moving to development of information technology. Every time technological progress of mankind, will bring about changes on the design activities. Digital technology as the most important achievements of this era vision, visual art and design being directed to a broader area. Contemporary visual art and design is no longer the time before the Internet era, in a single visual media in a single form of expression to design, but designed in a way to integrate, on an interactive multimedia platform, expand design activities, and a variety of effects to affect perception and moved the audience to get the best of conveying effect.

In addition, the Internet space includes a variety of non-physical form, such as business promotion, blog, virtual community, games, media activities, education, learning, and so on. In traditional industries are rapidly internalized into the Internet platform, but a variety of new virtual and virtual goods industries have also been developed. Digital interfaces for virtual product design to create new visual arts content eleven web design, interface design, interactive design, new visual design category, these are the new technologies applied to the birth of new media design product. Meanwhile, the virtual interface platform of the Internet spawned by the many channels of information dissemination, but also for the visual brand image design and publicity provided a rare opportunity to flourish in the new century.

\section{Conclusions}

In the context of the digital information age, visual brand image design demands constantly shift, brand image and design language of communication are moving in the direction of diversification, these have become the Chinese brand visual identity design future The main trend. Should see the visual brand image design is a systematic integration of the design process, and the visual image of the design is also to be applied in almost brand communication, its importance can be imagined. Not difficult to see from the brand image design development process of technological innovation as a useful design offer. Information dissemination speed text and graphics, images, etc., can greatly improve the brand promotion design. New media, especially online media, to spread the brand image to provide a broader channels and means, building a website is to provide an updated platform, and a wider audience.

\section{References}

[1] Meng Tao, brand networking with cluster [J], Dong bei University of Finance and Economics, 2006 (2): 14-16.

[2] Chris Willis, Shayne Bowman. We Media [R]. The Media Center of American Press Institute, 2007.

[3] Christian Dussart. Transformation Power of e-Business over consumer brands. [J]. European management journal, 2011 (19): 629-637.

[4] Dame C.Ward, Amy L. Ostrom. The Internet as information minefield, analysis of the source and content of brand information yielded by net searches [J],journal of business research, 2013 (56): 907-914.

[5] Morrison, A.M, Taylor, 3.S, and Douglas. A. Website evaluation in tourism and hospitality: The art is not yet stated[J]. Journal of Travel \& Tourism Marketing: 2014 420-425. 